Article

\title{
Functional Evaluation Using Fuzzy FMEA for a Non-Invasive Measurer for Methane and Carbone Dioxide
}

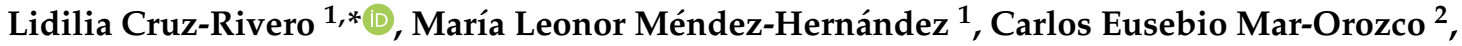 \\ Alberto A. Aguilar-Lasserre ${ }^{3} \mathbb{D}$, Alfonso Barbosa-Moreno ${ }^{2}$ and Josué Sánchez-Escobar ${ }^{1}$ \\ 1 Instituto Tecnológico Superior de Tantoyuca, National Technological Institute of Mexico, \\ Veracruz 92100, Mexico; draleonormendez@gmail.com (M.L.M.-H.); josue_se@outlook.es (J.S.-E.) \\ 2 Instituto Tecnológico de Ciudad Madero, National Technological Institute of Mexico, Veracruz 92100, Mexico; \\ carlos.mar.orozco@gmail.com (C.E.M.-O.); a.barbosa.moreno@gmail.com (A.B.-M.) \\ 3 Instituto Tecnológico de Orizaba, National Technological Institute of Mexico, Veracruz 92100, Mexico; \\ albertoaal@hotmail.com \\ * Correspondence: lilirivero@gmail.com; Tel.: +52-(789)-100-5673
}

Citation: Cruz-Rivero, L.; Méndez-Hernández, M.L.;

Mar-Orozco, C.E.; Aguilar-Lasserre,

A.A.; Barbosa-Moreno, A.;

Sánchez-Escobar, J. Functional

Evaluation Using Fuzzy FMEA for a

Non-Invasive Measurer for Methane

and Carbone Dioxide. Symmetry 2022,

14, 421. https://doi.org/10.3390/

sym14020421

Academic Editor: Basil

Papadopoulos

Received: 25 December 2021

Accepted: 16 February 2022

Published: 20 February 2022

Publisher's Note: MDPI stays neutral with regard to jurisdictional claims in published maps and institutional affiliations.

Copyright: (C) 2022 by the authors. Licensee MDPI, Basel, Switzerland. This article is an open access article distributed under the terms and conditions of the Creative Commons Attribution (CC BY) license (https:// creativecommons.org/licenses/by/ $4.0 /)$.

\begin{abstract}
This paper combines the use of two tools: Failure Mode and Effect Analysis (FMEA) and Fuzzy Logic (FL), to evaluate the functionality of a quantifier prototype of Methane gas $\left(\mathrm{CH}_{4}\right)$ and Carbon Dioxide $\left(\mathrm{CO}_{2}\right)$, developed specifically to measure the emissions generated by cattle. Unlike previously reported models for the same purpose, this device reduces damage to the integrity of the animal and does not interfere with the activities of livestock in their development medium. FMEA and FL are used to validate the device's functionality, which involves identifying possible failure modes that represent a more significant impact on the operation and prevent the prototype from fulfilling the function for which it was created. As a result, this document presents the development of an intelligent fuzzy system type Mamdani, supported in the Fuzzy Inference System Toolbox of MatLabR2018b ${ }^{\circledR}$, for generating a risk priority index. A Fuzzy FMEA model was obtained to validate the prototype for measuring Methane and Carbon Dioxide emissions, which allows considering this prototype as a reliable alternative for the reliable measurement of these gases. This study was necessary as a complementary part in the validation of the design of the prototype quantifier of $\mathrm{CH}_{4}$ and $\mathrm{CO}_{2}$ emissions. The methods used (classic FMEA and Fuzzy FMEA) to evaluate the RPN show asymmetric graphs due to data disparity. Values in the classical method are mostly lower than the Mamdani model results due to the description of the criteria with which it is evaluated.
\end{abstract}

Keywords: FMEA; Fuzzy Logic; greenhouse gases

\section{Introduction}

There are methodologies applied to security and reliability engineering, which include fuzzy FMEA, fuzzy Bayesian networks, fuzzy Markov chains, to name a few. When developing prototypes, it is not always possible to obtain fully reliable data due to the unavailability of primary observations and the consequent scarcity of data on the failure of their components [1]. To handle such situations, fuzzy set theory has been used successfully in approaches to security and reliability evaluation under conditions of uncertainty.

The use of Fuzzy Logic to help decision-making was applied in health in conjunction with the Failure Mode and Effects Analysis (FMEA) to improve decision-making. This was achieved by improving the way patients were processed before the study, the assessment, and treatment assignment; the use of Fuzzy Logic in the application of the FMEA was considered better than its conventional use [2]. The use of software to manage the risks of failure in medical equipment was developed around the use of the FMEA; it is described that the classic use of the FMEA is not enough to achieve an accurate analysis, so, in this case, additionally the use of the Fuzzy Logic was made to replace how the three main parameters of the FMEA are evaluated [3]. FMEA has been applied extensively in the 
reliability engineering domain. Risk Priority Number (RPN), which is the product of Occurrence (O), Severity (S), and Detection (D) of a failure, is the most important measure used in FMEA for prioritizing risk, and they integrate fuzzy belief structure and grey relational projection method (GRPM) to avoid the use of traditional RPN [4].

According to work "An extension to fuzzy developed failure mode and effect analysis FDFMEA application for aircraft landing system," the use of FMEA methodology and Fuzzy Logic was implemented for the evaluation of commercial aircraft in Iran, as described in this work; the main focus of the study was the analysis of the components of the landing systems since a large number of failures were recorded annually, in addition to the results of the Fuzzy Logic model also evaluated by the conventional method to offer a comparison of the results, the defuzzification method applied to the Fuzzy Logic model was Center of Gravity and for the construction of the model five participating experts to describe according to their knowledge the elements of evaluation of Severity, Occurrence, and Detection, and with the results, it was possible to establish measures and prioritize failures [5].

In the analysis of a lathe-type polishing machine, the fuzzy approach with the FMEA was also used, in this case, to improve reliability, because one of the most important parts of the entire polishing system presented a series of failures, and it was considered to individually evaluate the components of this part of the machine. As in other works, a model of Fuzzy Logic was used, and some of the important data that are mentioned in work around the use of the FMEA are that conventional use considers the evaluation of RPN almost equally in the evaluation criteria of Severity, Occurrence, and Detection; since these are pre-established, the assessment of the RPN is inadequate, instead they consider that each criterion should be based around the context of this problem with different weights and that these should also be established at the discretion of the experts in the field, so the use of Fuzzy Logic was chosen to improve this part of the methodology [6].

Greenhouse Gas (GHG) emissions are an important factor contributing to current climate change; it is said that of the sources that contribute to the increase in emissions due to livestock activities [7], the breeding of cattle is pointed out as one of the activities of this sector that contributes the most in emissions, although in the absence of reliable monitoring methods there is imprecision in terms of the data reported worldwide, and due to this different works have been done to quantify the emissions of livestock, through the creation of measurement devices to determine more precisely to what extent livestock influences emissions; however, according to this work reporting on this type of device, these have not been suitable for: the comfort and integrity of the animal and neither to measure in the natural conditions where cattle usually develop.

A device capable of belching $\mathrm{CO}_{2}$ and $\mathrm{CH}_{4}$ gas emissions from cattle was developed since, at the time in Mexico, there were no reports about the development of this type of device, and due to the cattle ranching activity present in several of the states, one of them was the state of Veracruz. The only countries that documented the development of this type of device were the United States, Colombia, and Argentina [8].

The prototype was statistically analyzed to verify that the proposed design is functional [9]. This device presents an alternative to measure GHG without harming the animal; however, it is necessary to carry out functionality studies, so an FMEA is used to evaluate the possibilities of failures, to explain the possible causes and the effects they can represent.

The application of the FMEA in conjunction with the Artificial Intelligence technique called Fuzzy Logic (FL), is proposed to ensure the correct functioning of the prototype through a functional evaluation, which implies identifying possible failure modes that represent a more significant impact on the operation and prevent the prototype from fulfilling the function for which it was created. The FL, in this case, is used to address the imprecision of the evaluation criteria of the classic FMEA and adapt them to the specific problem and facilitate the evaluation process commonly used in this tool. In this case, the prototype quantifier of gas emissions was put into operation in a group of cows previously selected to carry out a series of measurement tests; during the realization of these tests, different failures were observed in the equipment, and possible failure modes 
were considered, creating uncertainty about the correct functioning of the other elements that make up the device and the possibility that these may fail at a certain time and affect the measurements.

Due to the behaviors that cattle perform, especially in natural development conditions, several parts of the device are exposed to situations that represent a certain degree of risk for the proper functioning of the device, and the possibility of risk to failure in some elements was unknown before the performance of the tests of the quantifier. During the trials carried out, they resulted in damage: sensors, connectors, and the support structure that holds the device to the cow; these failures caused mostly inaccuracy in the measurements as verified after repairing some of these failures.

This work aims to know and assess the risk of possible failure modes, causes, and effects of a device that quantifies carbon dioxide $\left(\mathrm{CO}_{2}\right)$ and methane $\left(\mathrm{CH}_{4}\right)$ emissions from cattle; through the use of the Failure Mode and Effect Analysis (FMEA) and Fuzzy Logic (LD) methodology.

Currently, the application of the FMEA methodology has been extended in different areas and adapted to specific needs. However, it is generally recognized that there are four types of FMEA: system, design, process, and service [10]. Failure mode and effects analysis (FMEA) is a typical prevention reliability analysis method that has an inherent advantage in improving systems and processes. However, traditional FMEA also contains some deficiencies in rating risks, weighing risk factors, and ranking failure modes [11].

To overcome the inherent drawbacks of the conventional FMEA method and the uncertainty regarding the experts' evaluation, fuzzy methods, for example, triangular/trapezoidal and fuzzy sets, have been developed [12].

As mentioned by $[2,13]$, combining the FMEA method with fuzzy theory provides a more efficient tool than the classic FMEA method in the presence of imprecise information and uncertainty. Fuzzy Logic could be used to reduce the drawback in assessing and prioritizing failures of traditional FMEA with more certainty.

Fuzzy Logic is a technique that allows us to represent and manipulate some variables' imprecise and uncertain nature. However, its use is not limited only to these variables but also to those that are known and precise to a certain degree; the technique allows us to make these types of variables coexist mainly in cases of decision making and the development of intelligent systems, cases where imprecision and uncertainty modeling is necessary and also the inclusion of known variables for a joint analysis.

In a work related to fuzzy FMEA assessment of hydroelectric earth dam failure modes, the rule bases for the two stages and the membership functions were obtained through in-depth interviews with a focus group composed of experts. The fuzzification process assured more consistency to the RPN calculation, treated the imprecision, and provided fair management value to prioritize actions and improve monitoring processes [14], which is the goal of this proposed work.

The use of analysis methods such as classic FMEA to assess the safety and reliability of a system relies heavily on knowledge of component failure. Any uncertainty that arises in the probability of component failure will impact the results [1]. On the other hand, the lack of availability of failure data would introduce uncertainty in the analysis results in this sense. To reduce this uncertainty, it is proposed to use fuzzy FMEA.

\section{Materials and Methods}

\subsection{Prototype Description}

The prototype to be evaluated fulfills the primary function of estimating the emissions of gases that cattle generate and exhale, specifically those of $\mathrm{CO}_{2}$ and $\mathrm{CH}_{4}$ gas, the main components in this device are: an emitter and a receiver; in turn, the subcomponents are: a battery, a support structure that adjusts to the characteristics of the bovine tube, two sensors that quantify gas emissions, straps that attach the support structure and other components to the head of the animal and the receiver which is connected to the computer to record the 
information of the measurements. The following image shows the device as well as the installation in cattle (Figure 1).
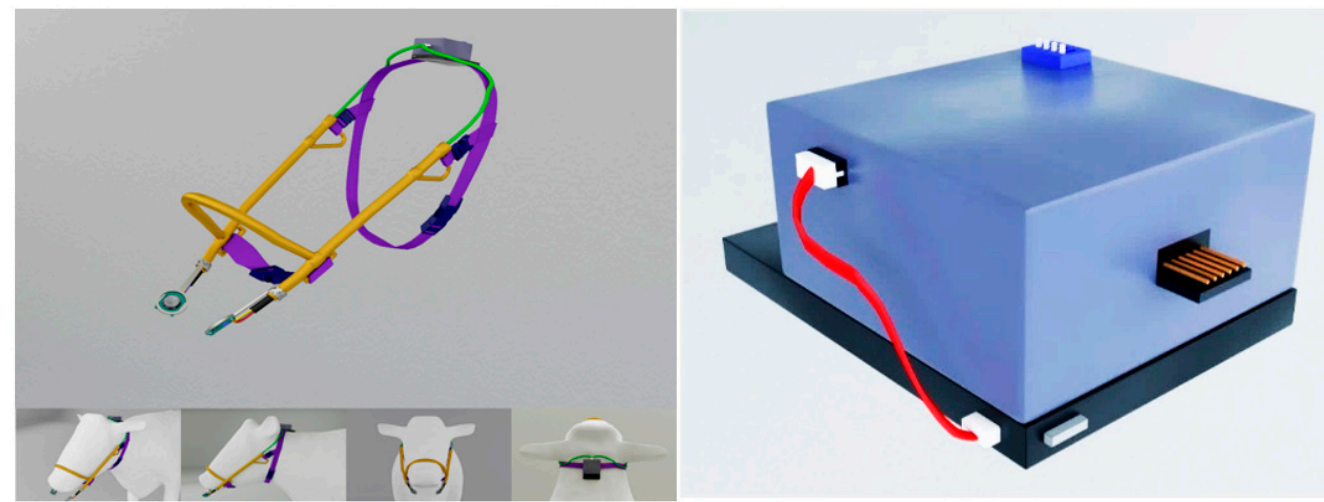

Figure 1. Gas emission quantifier for cattle. Source: Retrieved from Autodesk 3ds Max, self-made content.

Components associated with major failures and representing a negative impact on the operation of the quantifier were strategically selected (Table 1).

Table 1. Elements selected for the development of the fault study Receiver Sender.

\begin{tabular}{cc}
\hline Receiver & Sender \\
\hline Emitter-battery connection & Receiver-computer connection \\
Emitter-sensor connection & Receiver DIP \\
Issuer's DIP & On-screen light trimmer potentiometer \\
Battery & XBee Coordinator Module \\
Straps & \\
Support structure & \\
Sensors & \\
Sensor holder & \\
XBee Router Module & \\
\hline
\end{tabular}

The proposed framework for dealing with fuzzy FMEA is illustrated in Figure 2. The framework comprises three main phases, including (1) prototype components under study; (2) classic FMEA development; (3) determining the NPR through a Mamdani-type Fuzzy Logic model; (4) fuzzification process; and (5) defuzzification.

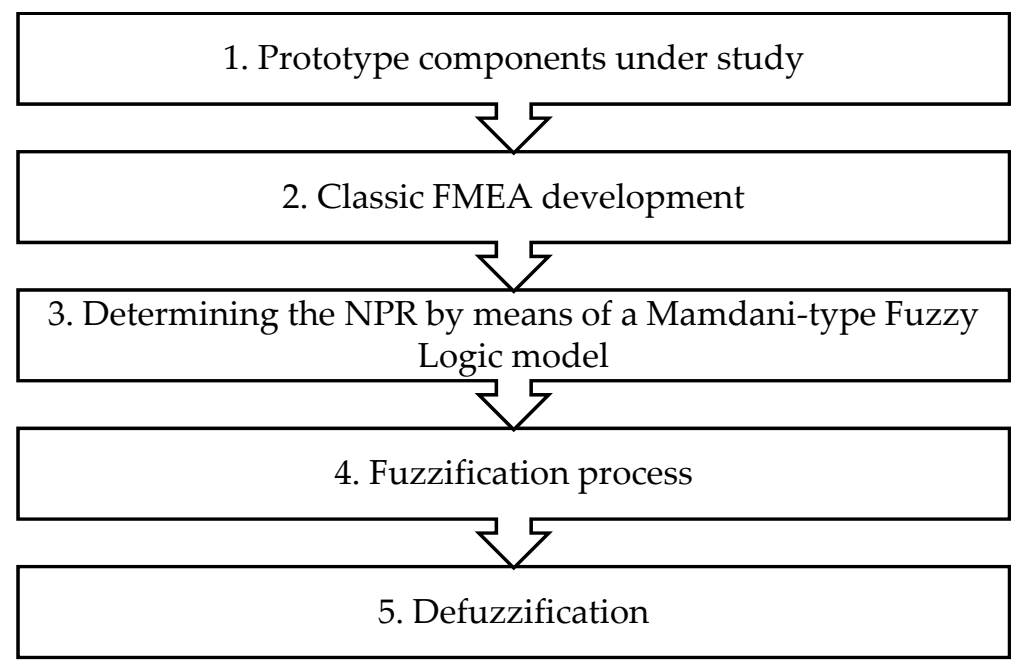

Figure 2. The methodology flowchart. 


\subsection{Classic FMEA Development}

For the development of the FMEA, those components associated with important faults and that represent a great negative impact on the operation of the quantifier was selected. For the selection of the necessary elements to carry out the prototype failure risk study, first, a group of specialists participating in the design of the device was the ones who, through brainstorming, managed to generate a list of both potential components and subcomponents for the study, after an analysis based on the relationship of components and their importance in the operation, it was possible to prioritize the said list, the resulting elements that will be used for the development of the study are shown below (Table 2).

Table 2. Classic FMEA.

\begin{tabular}{|c|c|c|c|c|c|}
\hline $\begin{array}{l}\text { Main } \\
\text { Component }\end{array}$ & Subcomponent & No & Failure Mode & Causes of Failure & Failure Effects \\
\hline \multirow{3}{*}{ Emitter } & \multirow{3}{*}{ Battery-emitter line } & 1 & $\begin{array}{l}\text { Unplugging } \\
\text { connectors }\end{array}$ & $\begin{array}{l}\text { Line exposed to the outside of the } \\
\text { emitter stuck with objects in the } \\
\text { environment. }\end{array}$ & $\begin{array}{l}\text { Emitter and sensors out of } \\
\text { operation due to lack of electrical } \\
\text { power supply, interruption of } \\
\text { measurements. }\end{array}$ \\
\hline & & 2 & False in connectors & $\begin{array}{l}\text { Non-fixed plug-type connectors, } \\
\text { contact of the line with the animal's } \\
\text { body or objects in the environment. }\end{array}$ & $\begin{array}{l}\text { Electric current and intermittent } \\
\text { emitter operation, uncalibrated } \\
\text { sensor, discontinuous and incorrect } \\
\text { data sending. }\end{array}$ \\
\hline & & 3 & Short circuit & $\begin{array}{l}\text { Connectors discovered outdoors, } \\
\text { the humidity of the environment, or } \\
\text { animal fluids. }\end{array}$ & $\begin{array}{c}\text { Partial or total damage to internal } \\
\text { components of the emitter and/or } \\
\text { battery. }\end{array}$ \\
\hline \multirow{3}{*}{ Emitter } & \multirow{3}{*}{ Emitter-sensor line } & 4 & $\begin{array}{l}\text { Unplugging } \\
\text { connectors }\end{array}$ & $\begin{array}{l}\text { Line exposed to the outside of the } \\
\text { emitter, inadequate line length, line } \\
\text { stuck with objects in the } \\
\text { environment. }\end{array}$ & $\begin{array}{l}\text { Sensors out of operation due to lack } \\
\text { of electrical power supply. }\end{array}$ \\
\hline & & 5 & False in connectors & $\begin{array}{l}\text { Non-fixed plug-type connectors, } \\
\text { contact of the line with the animal's } \\
\text { body or objects in the environment. }\end{array}$ & $\begin{array}{l}\text { Electric current and intermittent } \\
\text { sensor operation, sensor } \\
\text { uncalibrated, incorrect and } \\
\text { discontinuous measurements. }\end{array}$ \\
\hline & & 6 & Short circuit & $\begin{array}{l}\text { Connectors discovered outdoors, } \\
\text { ambient humidity, or animal fluids. }\end{array}$ & $\begin{array}{c}\text { Partial or total damage to the } \\
\text { sensors and/or internal controllers } \\
\text { of the emitter. }\end{array}$ \\
\hline \multirow{3}{*}{ Emitter } & \multirow{3}{*}{ Emitter DIP } & 7 & $\begin{array}{l}\text { Inactive electric } \\
\text { current function }\end{array}$ & $\begin{array}{l}\text { Switch exposed to the elements, } \\
\text { deactivated by contact with the } \\
\text { animal's body or objects in the } \\
\text { environment. }\end{array}$ & $\begin{array}{l}\text { The passage of electric current from } \\
\text { the emitter to each of the sensors is } \\
\text { not allowed; the sensors will not } \\
\text { make measurements. }\end{array}$ \\
\hline & & 8 & $\begin{array}{l}\text { Inactive ground } \\
\text { current function }\end{array}$ & $\begin{array}{l}\text { Switch exposed to the elements, } \\
\text { deactivated by contact with the } \\
\text { animal's body or objects in the } \\
\text { environment. }\end{array}$ & $\begin{array}{c}\text { Emitter components and sensors are } \\
\text { vulnerable to damage from } \\
\text { electrical surges. }\end{array}$ \\
\hline & & 9 & $\begin{array}{l}\text { Inactive } \mathrm{TX} \text { radio } \\
\text { frequency function }\end{array}$ & $\begin{array}{l}\text { Switch exposed to the elements, } \\
\text { deactivated by contact with the } \\
\text { animal's body or objects in the } \\
\text { environment. }\end{array}$ & $\begin{array}{l}\text { The sensors perform measurements, } \\
\text { but the XBee Coordinator module } \\
\text { does not transmit the data to the } \\
\text { receiver for data recording. }\end{array}$ \\
\hline \multirow[t]{3}{*}{ Emitter } & & 10 & $\begin{array}{l}\text { Inactive } \mathrm{TX} \text { radio } \\
\text { frequency function }\end{array}$ & $\begin{array}{l}\text { Switch exposed to the elements, } \\
\text { deactivated by contact with the } \\
\text { animal's body or objects in the } \\
\text { environment. }\end{array}$ & $\begin{array}{l}\text { The signal of the measurements is } \\
\text { transmitted from the XBee } \\
\text { Coordinator module, but } \\
\text { communication with the XBee } \\
\text { Router module of the receiver is not } \\
\text { achieved. }\end{array}$ \\
\hline & & 11 & Fractured switches & $\begin{array}{l}\text { Exposed switch location, sudden } \\
\text { movements of the animal, or } \\
\text { improper handling of the operator. }\end{array}$ & $\begin{array}{l}\text { Difficulty manipulating the } \\
\text { functions of the switches in the } \\
\text { emitter. }\end{array}$ \\
\hline & & 12 & Short circuit & $\begin{array}{l}\text { Connectors discovered outdoors, } \\
\text { ambient humidity, or animal fluids. }\end{array}$ & $\begin{array}{l}\text { Instability of functions, damage of } \\
\text { emitter components. }\end{array}$ \\
\hline
\end{tabular}


Table 2. Cont.

\begin{tabular}{|c|c|c|c|c|c|}
\hline $\begin{array}{c}\text { Main } \\
\text { Component }\end{array}$ & Subcomponent & No & Failure Mode & Causes of Failure & Failure Effects \\
\hline \multirow{2}{*}{ Emitter } & \multirow{2}{*}{ Battery } & 13 & Thermal leakage & $\begin{array}{l}\text { The inadequate protective case } \\
\text { against high or low temperatures. }\end{array}$ & $\begin{array}{c}\text { Poor battery performance, } \\
\text { interruption of measurements, } \\
\text { incomplete measurement periods. }\end{array}$ \\
\hline & & 14 & Short circuit & $\begin{array}{l}\text { Lack of tightness, broken protective } \\
\text { sheath, moisture filtration from the } \\
\text { environment, or animal fluids. }\end{array}$ & $\begin{array}{l}\text { Damage to emitter box components } \\
\text { and/or sensors. }\end{array}$ \\
\hline \multirow[b]{2}{*}{ Emitter } & \multirow{2}{*}{ Straps } & 15 & Loose safety clasps & $\begin{array}{l}\text { Animal struggle, poor operator fit, } \\
\text { or poorly resistant plastic material. }\end{array}$ & $\begin{array}{l}\text { Instability of the structure at the } \\
\text { animal head or loose structure of the } \\
\text { animal head. }\end{array}$ \\
\hline & & 16 & $\begin{array}{l}\text { Breaking of security } \\
\text { bands }\end{array}$ & $\begin{array}{c}\text { Friction wear, moisture } \\
\text { deterioration, sudden movement of } \\
\text { the animal, or low resistance of the } \\
\text { material. }\end{array}$ & $\begin{array}{l}\text { Instability of the structure at the head } \\
\text { of the animal or loose structure of the } \\
\text { head of the animal. }\end{array}$ \\
\hline \multirow[t]{2}{*}{ Emitter } & \multirow[t]{2}{*}{ Support structure } & 17 & Folded metal arms & $\begin{array}{l}\text { Flexible material, animal struggle, } \\
\text { or operator mismanagement. }\end{array}$ & $\begin{array}{l}\text { Improper position of the sensor to the } \\
\text { animal's tube, low sensor } \\
\text { measurement range, unreliable gas } \\
\text { estimates with a high level of } \\
\text { variation. }\end{array}$ \\
\hline & & 18 & $\begin{array}{l}\text { Desoldered arm } \\
\text { joints }\end{array}$ & $\begin{array}{c}\text { Poor welding work, poorly resistant } \\
\text { welding, or overexertion of the } \\
\text { structure. }\end{array}$ & $\begin{array}{l}\text { Instability of the structure at the head } \\
\text { of the animal or loose structure of the } \\
\text { head of the animal. }\end{array}$ \\
\hline \multirow{3}{*}{ Emitter } & \multirow{3}{*}{ Sensors } & 19 & $\begin{array}{l}\text { Low measurement } \\
\text { sensitivity }\end{array}$ & $\begin{array}{l}\text { Obstruction of the sensor by food } \\
\text { debris or mucus from the animal, } \\
\text { poor posture, and strong wind } \\
\text { currents. }\end{array}$ & $\begin{array}{l}\text { Unreliable gas estimates with a high } \\
\text { level of variation. }\end{array}$ \\
\hline & & 20 & Short circuit & $\begin{array}{l}\text { The printed circuit of the discovered } \\
\text { sensor, ambient humidity, animal } \\
\text { mucus, or food debris. }\end{array}$ & $\begin{array}{l}\text { Instability of electric current in } \\
\text { sensors, discontinuous measurement } \\
\text { lapses, the partial or total damage to } \\
\text { the sensor. }\end{array}$ \\
\hline & & 21 & $\begin{array}{l}\text { Led measurement } \\
\text { indicator without } \\
\text { operating. }\end{array}$ & $\begin{array}{l}\text { Led desoldering of the printed } \\
\text { circuit, damaged by moisture or } \\
\text { melted by shocks. }\end{array}$ & $\begin{array}{l}\text { Difficulty identifying sensor } \\
\text { malfunction in real-time. }\end{array}$ \\
\hline \multirow[t]{2}{*}{ Emitter } & \multirow[t]{2}{*}{ Sensor holder } & 22 & Bent structure & $\begin{array}{l}\text { Slightly rigid structural material, } \\
\text { sudden movements of the animal's } \\
\text { tube, and/or the wrong fit in the } \\
\text { animal's tube. }\end{array}$ & $\begin{array}{l}\text { Improper position of the sensor to the } \\
\text { animal's tube, low sensor } \\
\text { measurement range, unreliable gas } \\
\text { estimates with a high level of } \\
\text { variation. }\end{array}$ \\
\hline & & 23 & $\begin{array}{l}\text { Loose Assembly } \\
\text { Snaps }\end{array}$ & $\begin{array}{l}\text { Sudden movements of the animal's } \\
\text { trunk and obstruction with objects } \\
\text { in the environment. }\end{array}$ & $\begin{array}{c}\text { Instability of sensors to the animal's } \\
\text { trunk. }\end{array}$ \\
\hline Receiver & $\begin{array}{l}\text { XBee Modules } \\
\text { (Router and } \\
\text { Coordinator) }\end{array}$ & 24 & $\begin{array}{l}\text { Communication } \\
\text { signal loss }\end{array}$ & $\begin{array}{l}\text { Unfavorable topographical } \\
\text { conditions, interference from other } \\
\text { signals, or low range capability of } \\
\text { the modules. }\end{array}$ & $\begin{array}{c}\text { Gas measurement data loss during } \\
\text { signal interruption between XBee } \\
\text { modules. }\end{array}$ \\
\hline \multirow{4}{*}{ Receiver } & \multirow{4}{*}{ Receiver DIP } & 25 & $\begin{array}{l}\text { Inactive electric } \\
\text { current function }\end{array}$ & $\begin{array}{l}\text { Operator mishandling or fractured } \\
\text { switch. }\end{array}$ & $\begin{array}{l}\text { The passage of electric current from } \\
\text { the computer is not allowed, difficulty } \\
\text { manipulating the functions of the } \\
\text { switches. }\end{array}$ \\
\hline & & 26 & $\begin{array}{l}\text { Inactive grounding } \\
\text { function }\end{array}$ & $\begin{array}{l}\text { Operator mishandling or fractured } \\
\text { switch. }\end{array}$ & $\begin{array}{l}\text { In case of short circuit damage of the } \\
\text { receiver components, difficulty } \\
\text { manipulating the functions of the } \\
\text { switches. }\end{array}$ \\
\hline & & 27 & $\begin{array}{l}\text { Inactive TX radio } \\
\text { frequency function }\end{array}$ & $\begin{array}{l}\text { Operator mishandling or fractured } \\
\text { switch. }\end{array}$ & $\begin{array}{l}\text { The receiver does not send back the } \\
\text { communication signal to the } \\
\text { transmitter, having difficulty } \\
\text { manipulating the switches' functions. }\end{array}$ \\
\hline & & 28 & $\begin{array}{l}\text { Inactive TX radio } \\
\text { frequency function }\end{array}$ & $\begin{array}{l}\text { Operator mishandling or fractured } \\
\text { switch. }\end{array}$ & $\begin{array}{l}\text { The receiver does not receive the } \\
\text { signal from the transmitter, difficulty } \\
\text { manipulating the functions of the } \\
\text { switches on the receiver. }\end{array}$ \\
\hline
\end{tabular}


Table 2. Cont.

\begin{tabular}{|c|c|c|c|c|c|}
\hline $\begin{array}{l}\text { Main } \\
\text { Component }\end{array}$ & Subcomponent & No & Failure Mode & Causes of Failure & Failure Effects \\
\hline Receiver & $\begin{array}{l}\text { Trimmer LCD } \\
\quad \text { Screen } \\
\text { Potentiometer }\end{array}$ & 29 & $\begin{array}{l}\text { Incorrect light } \\
\text { regulation }\end{array}$ & $\begin{array}{l}\text { The sweeping regulator, presence of } \\
\text { moisture or internal dirt. }\end{array}$ & $\begin{array}{l}\text { Difficulty manipulating the lighting } \\
\text { intensity on the receiver screen. }\end{array}$ \\
\hline Receiver & $\begin{array}{l}\text { Receiver-computer } \\
\text { connection }\end{array}$ & 30 & $\begin{array}{l}\text { Incorrect light } \\
\text { regulation }\end{array}$ & $\begin{array}{l}\text { Error in software drivers, operator } \\
\text { mishandling. }\end{array}$ & $\begin{array}{l}\text { Interruption in the transfer of } \\
\text { information, loss of data in the logger } \\
\text { software. }\end{array}$ \\
\hline
\end{tabular}

\subsection{NPR through a Mamdani-Type Fuzzy Logic Model3}

For the elaboration of the fuzzy FMEA model, the MatLabR2018b ${ }^{\circledR}$ LD toolbox was used. This toolbox made it possible to define a fuzzy system through dialogs and windows that facilitated data entry. A set of functions was available to analyze the behavior of these systems.

In the adaptation of the criteria and the RPN, it is also necessary to provide the linguistic or categorical values that serve as a reference to use as values that allow the Mamdani type model to assess rules; it is based on these values that the ranges of values will be considered representative by the specialists, which in fuzzification is where the categorical criteria will be modeled with these scales, geometric figures, and the criteria proposed for evaluation by specialists are those shown in the following table (Table 3).

Table 3. Adequacy of parameters for the assessment of the Risk Priority Number.

\begin{tabular}{|c|c|c|c|c|c|}
\hline $\begin{array}{l}\text { Linguistic } \\
\text { Value }\end{array}$ & Severity & $\begin{array}{l}\text { Linguistic } \\
\text { Value }\end{array}$ & Occurrence & $\begin{array}{l}\text { Linguistic } \\
\text { Value }\end{array}$ & Detection \\
\hline Very Low & $\begin{array}{l}\text { It does not represent } \\
\text { significant affectation; the } \\
\text { operation of the prototype } \\
\text { will be almost normal. }\end{array}$ & Remote & $\begin{array}{l}\text { Just once for each } \\
\text { measurement period. }\end{array}$ & Very High & $\begin{array}{c}\text { In most tests are } \\
\text { identified, detailed } \\
\text { inspections are not } \\
\text { necessary. }\end{array}$ \\
\hline Low & $\begin{array}{l}\text { It represents minimal } \\
\text { affectation; the prototype } \\
\text { will work with slight } \\
\text { affectations. }\end{array}$ & Low & $\begin{array}{l}\text { Approximately up to } \\
\text { three times for each } \\
\text { measurement period. }\end{array}$ & High & $\begin{array}{c}\text { They are almost always } \\
\text { detected in tests; no } \\
\text { detailed inspections are } \\
\text { necessary. }\end{array}$ \\
\hline Medium & $\begin{array}{l}\text { The affectations are } \\
\text { significant; the device will } \\
\text { work, the information } \\
\text { generated will be unreliable. }\end{array}$ & Regular & $\begin{array}{l}\text { Approximately up to } \\
\text { five times per } \\
\text { measurement period. }\end{array}$ & Medium & $\begin{array}{l}\text { Sometimes they are } \\
\text { detected during testing; } \\
\text { basic inspection is } \\
\text { necessary. }\end{array}$ \\
\hline High & $\begin{array}{l}\text { The affectations are severe; } \\
\text { sometimes, it will not work, } \\
\text { the information generated } \\
\text { will not be reliable. }\end{array}$ & High & $\begin{array}{l}\text { Approximately up to } \\
\text { seven times for each } \\
\text { measurement period. }\end{array}$ & Low & $\begin{array}{l}\text { Hardly detected during } \\
\text { testing, a detailed } \\
\text { inspection is necessary. }\end{array}$ \\
\hline Very High & $\begin{array}{l}\text { The affectations will not } \\
\text { allow the operation of the } \\
\text { prototype. }\end{array}$ & Very High & $\begin{array}{l}\text { More than seven for } \\
\text { each measurement } \\
\text { period. }\end{array}$ & Very Low & $\begin{array}{l}\text { They are seldom } \\
\text { detected during testing; } \\
\text { inspection with special } \\
\text { methods is necessary. }\end{array}$ \\
\hline
\end{tabular}

The Fuzzy Logic model is proposed to evaluate the risk of possible failures in the prototype; the construction is done around the variables used by the FMEA. The process for obtaining the risk or RPN is carried out through inference rules based on human knowledge.

\section{Model Architecture}

For this case study, the general architecture of the Pure Type Fuzzy System or Mamdani was used [15]. Mamdani fuzzy models do not require mathematical models of the system 
to control and are obtained from fuzzy rules or fuzzy conditional statements [16], like the one presented in this work. The structure of the fuzzy model poses input and output variables, with the inputs for this model being the evaluation criteria Severity, Occurrence, and Detection and output being the RPN indicator.

The development of the Mamdani model consists of three important processes [15]: fuzzification, the introduction of inference rules, and the defuzzification of the outputs. The following diagram represents the structure of this type of model applied to the case (Figure 3).

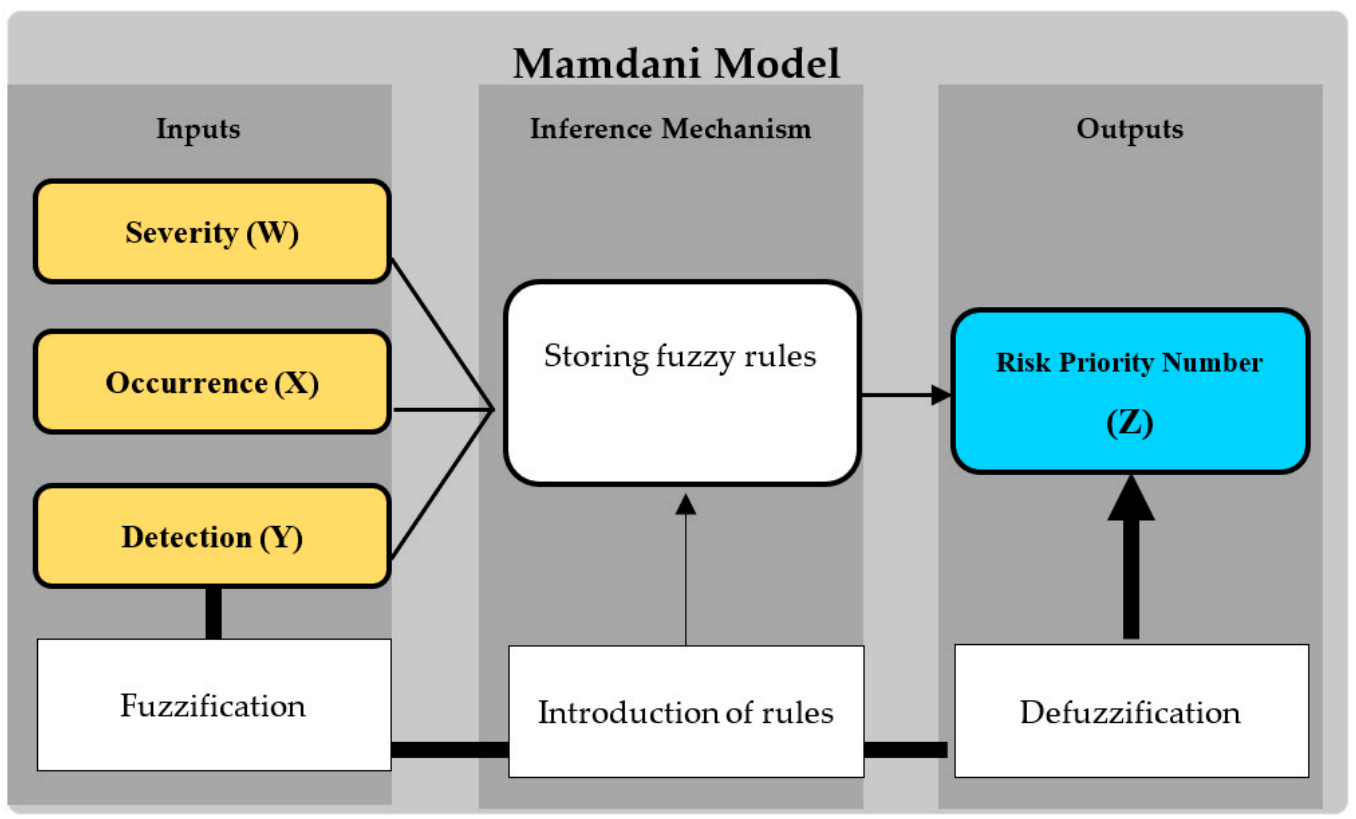

Figure 3. General diagram of the Mamdani Type Fuzzy Logic model for evaluating the quantifying prototype Source: Own elaboration.

\subsection{Fuzzification Process}

The fuzzification process is carried out for the input and output variables of the model, these being those of the FMEA: Severity, Occurrence, Detection and the RPN, for each variable, the geometric figures that best fit the membership function to the type of variable that is modeled are assigned, the approximate ranges of the variables are also established and are associated with linguistic values, being those that will represent the fuzzy sets of the Mamdani model.

The input variables for this model are Severity (W) (Table 4, Figure 4), Occurrence (X), and Detection $(\mathrm{Y})$. Based on these and from the resulting fuzzy sets, the inference rules that determine the corresponding output scenarios will be established; these variables in the model represent the evaluation parameters with which it is sought to analyze the risk or $\mathrm{RPN}(\mathrm{Z})$ of each of the rulings raised in the FMEA.

Table 4. Characteristics of the fuzzy sets of the input variable Severity (W).

\begin{tabular}{ccc}
\hline Fuzzy Sets & Fuzzy Range & Geometric Figures Values \\
\hline Very Low & $0-2$ & {$[0,0,1,2]$} \\
Low & $1-4$ & {$[1,2,3,4]$} \\
Medium & $3-6$ & {$[3,4,5,6]$} \\
High & $5-8$ & {$[5,6,7,8]$} \\
Very High & $7-10$ & {$[7,8,10,10]$} \\
\hline
\end{tabular}




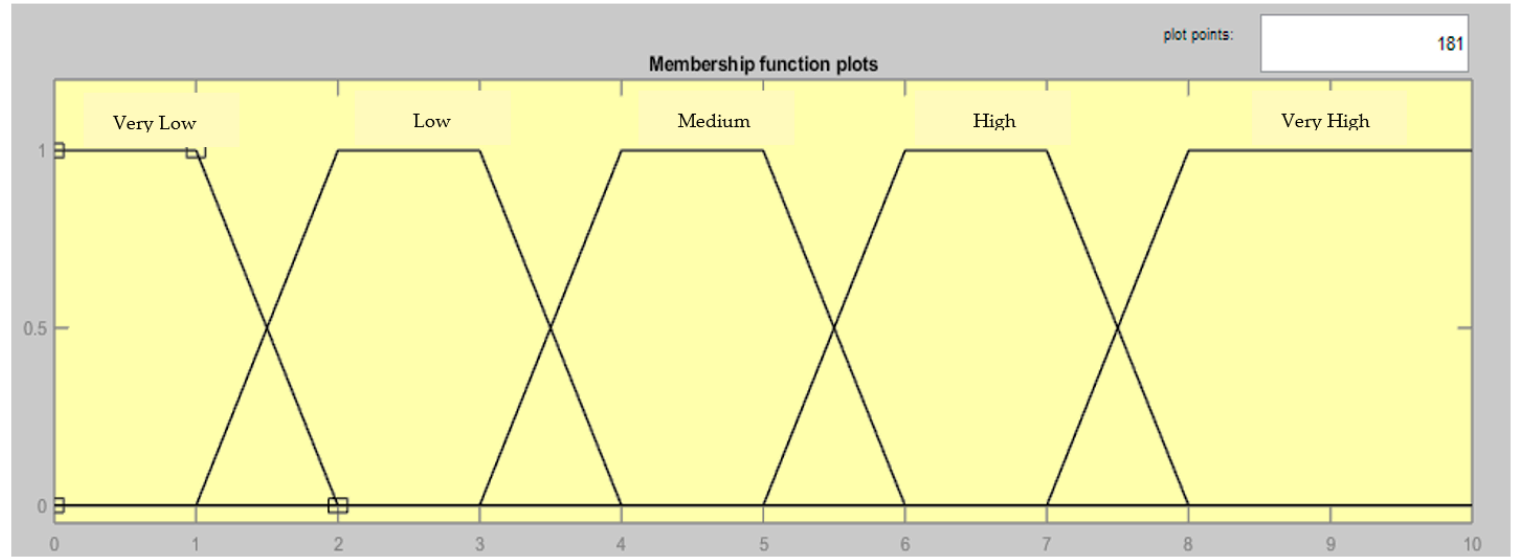

Figure 4. Fuzzy Sets Severity Variable (Retrieved from MATLAB R2018b, Screenshot of Membership Function Editor window, self-made content).

Equation (1). Severity Fuzzy Set “Very Low" (W).

$$
\mu_{\text {Very Low }}(\text { Severity })=\left\{\begin{aligned}
1 ; & \mathrm{W} \leq 1 \\
1-\frac{\mathrm{W}-1}{2-1} ; & 1<\mathrm{W}<2 \\
0 ; \quad & 2 \leq \mathrm{W}
\end{aligned}\right.
$$

Equation (2). Severity Fuzzy Set “Low” (W).

$$
\mu_{\text {Low }}(\text { Severity })=\left\{\begin{array}{c}
0 ; \quad \mathrm{W} \leq 1 \\
1-\frac{2-\mathrm{W}}{2-1} ; 1<\mathrm{W}<2 \\
1 ; 2 \leq \mathrm{W} \leq 3 \\
1-\frac{\mathrm{W}-3}{4-3} ; \quad 3<\mathrm{W}<4 \\
0 ; \quad 4 \leq \mathrm{W}
\end{array}\right.
$$

Equation (3). Severity Fuzzy Set "Medium" (W).

$$
\mu_{\text {Medium }}(\text { Severity })=\left\{\begin{array}{c}
0 ; \quad \mathrm{W} \leq 3 \\
1-\frac{4-\mathrm{W}}{4-3} ; \quad 3<\mathrm{W}<4 \\
1 ; 4 \leq \mathrm{W} \leq 5 \\
1-\frac{\mathrm{W}-5}{6-5} ; \quad 5<\mathrm{W}<6 \\
0 ; \quad 6 \leq \mathrm{W}
\end{array}\right.
$$

Equation (4). Severity Fuzzy Set “High” (W).

$$
\mu_{\text {High }}(\text { Severity })=\left\{\begin{array}{c}
0 ; \quad \mathrm{W} \leq 5 \\
1-\frac{6-\mathrm{W}}{6-5} ; 5<\mathrm{W}<6 \\
1 ; 6 \leq \mathrm{W} \leq 7 \\
1-\frac{\mathrm{W}-7}{8-7} ; 7<\mathrm{W}<8 \\
0 ; \quad 8 \leq \mathrm{W}
\end{array}\right.
$$

Equation (5). Severity Fuzzy Set “Very High” (W).

$$
\mu_{\text {Very High }}(\text { Severidad })=\left\{\begin{aligned}
0 ; & \mathrm{W} \leq 7 \\
1-\frac{8-\mathrm{W}}{8-7} ; & 7<\mathrm{W}<8 \\
1 ; & 8 \leq \mathrm{W}
\end{aligned}\right.
$$

In this model, the Occurrence was raised in considering the measurement periods, that is, to establish a reference metric on how often failures may occur in the prototype. The time in which it was used for the gas measurement studies in the cattle was taken into 
account, which in this case was per week: 5 days of measurement and two days of rest, and for each day of measurement, two tests were taken so that in a measurement period the prototype was used on ten occasions, in this context it is that the scale was established regarding the failures that occurred and from this, it was possible to relate the frequency to categorical values that qualify the occurrence. As a result, the following fuzzy sets are proposed with the representative ranges of each geometric figure (Table 5).

Table 5. Characteristics of the fuzzy sets of the input variable Occurrence $(X)$.

\begin{tabular}{ccc}
\hline Fuzzy Sets & Fuzzy Range & Geometric Figures Values \\
\hline Remote & $0-2$ & {$[0,0,1,2]$} \\
Low & $1-4$ & {$[1,2,3,4]$} \\
Regular & $3-6$ & {$[3,4,5,6]$} \\
High & $5-8$ & {$[5,6,7,8]$} \\
Very High & $7-10$ & {$[7,8,10,10]$} \\
\hline
\end{tabular}

The detection variable represents the ease with which the prototype operator can identify the failure modes during the tests and/or after the tests, the scale established as in the conventional way reaches up to 10, for this case the sets associated with such a scale are the following (Table 6).

Table 6. Characteristics of the fuzzy sets of the input variable Detection $(\mathrm{Y})$.

\begin{tabular}{ccc}
\hline Fuzzy Sets & Fuzzy Range & Geometric Figures Values \\
\hline Very High & $0-2$ & {$[0,0,1,2]$} \\
High & -4 & {$[1,2,3,4]$} \\
Medium & $3-6$ & {$[3,4,5,6]$} \\
Low & $5-8$ & {$[5,6,7,8]$} \\
Remote & $7-10$ & {$[7,8,10,10]$} \\
\hline
\end{tabular}

\section{Results}

\subsection{Risk Priority Number}

For the RPN output variable, it was considered appropriate to use seven fuzzy sets associated with linguistic terms and denoting a category that allows evaluating the intensity of the variable (Table 7), the scale that is used for the sets, as well as that used in the classic FMEA, is up to 1000 , to make a comparison or make symmetry analysis between the results of the Mamdani model and those of the conventional method (Figure 5).

Table 7. Characteristics of the fuzzy sets of the output variable Risk Priority Number (Z).

\begin{tabular}{ccc}
\hline Fuzzy Sets & Fuzzy Range & Geometric Figures Values \\
\hline Very Low & $0-250$ & {$[0,125,250]$} \\
Low & $125-375$ & {$[125,250,375]$} \\
Significant & $250-500$ & {$[250,375,500]$} \\
Middle & $375-625$ & {$[375,500,625]$} \\
Predominant & $500-750$ & {$[500,625,750]$} \\
High & $625-875$ & {$[625,750,875]$} \\
Very high & $750-1000$ & {$[750,875,1000]$} \\
\hline
\end{tabular}




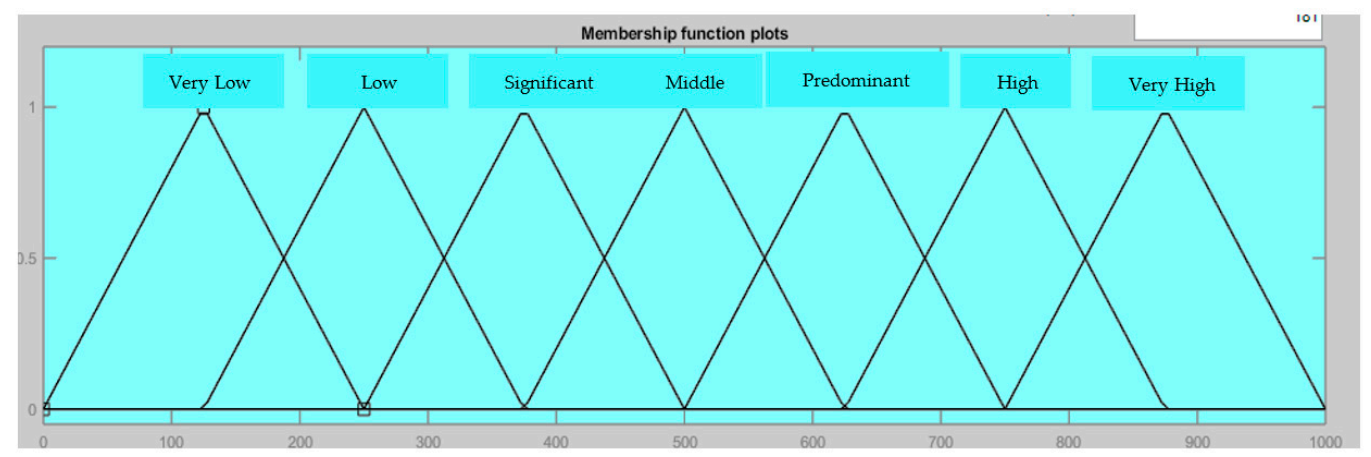

Figure 5. Fuzzy sets of the Risk Priority Number variable; Source: Retrieved from MATLAB R2018b, Screenshot of Membership Function Editor window, self-made content.

Equation (6). RPN Fuzzy Set “Very Low" (Z).

$$
\mu_{\text {Very Low }}(R P N)=\left\{\begin{aligned}
0 ; & \mathrm{Z} \leq 0 \\
1-\frac{125-\mathrm{Z}}{125-0} ; & 0<\mathrm{Z} \leq 125 \\
1-\frac{\mathrm{Z}-125}{250-125} ; & 125<\mathrm{Z}<250 \\
0 ; & 250 \leq \mathrm{Z}
\end{aligned}\right.
$$

Equation (7). RPN Fuzzy Set “Low” (Z).

$$
\mu_{\text {Low }}(R P N)=\left\{\begin{array}{c}
0 ; \quad Z \leq 125 \\
1-\frac{250-Z}{250-125} ; \quad 125<\mathrm{Z} \leq 250 \\
1-\frac{Z-250}{375-250} ; \quad 250<\mathrm{Z}<375 \\
0 ; \quad 375 \leq \mathrm{Z}
\end{array}\right.
$$

Equation (8). RPN Fuzzy Set "Significant" (Z).

$$
\mu_{\text {Significant }}(R P N)=\left\{\begin{array}{c}
0 ; \quad \mathrm{Z} \leq 250 \\
1-\frac{375-\mathrm{Z}}{375-250} ; \quad 250<\mathrm{Z} \leq 375 \\
1-\frac{\mathrm{Z}-375}{250-375 ;} \quad 375<\mathrm{Z}<500 \\
0 ; \quad 500 \leq \mathrm{Z}
\end{array}\right.
$$

Equation (9). RPN Fuzzy Set "Middle" (Z).

$$
\mu_{\text {Middle }}(N P R)=\left\{\begin{array}{c}
0 ; \quad \mathrm{Z} \leq 375 \\
1-\frac{375-\mathrm{Z}}{375-250} ; \quad 375<\mathrm{Z} \leq 500 \\
1-\frac{\mathrm{Z}-375}{250-375} ; \quad 500<\mathrm{Z}<625 \\
0 ; \quad 625 \leq \mathrm{Z}
\end{array}\right.
$$

Equation (10). RPN Fuzzy Set "Predominant" (Z).

$$
\mu_{\text {Predominant }}(N P R)=\left\{\begin{array}{c}
0 ; \quad \mathrm{Z} \leq 500 \\
1-\frac{625-\mathrm{Z}}{625-500} ; \quad 500<\mathrm{Z} \leq 625 \\
1-\frac{\mathrm{Z}-625}{750-625} ; \quad 625<\mathrm{Z}<750 \\
0 ; \quad 750 \leq \mathrm{Z}
\end{array}\right.
$$

Equation (11). RPN Fuzzy Set “High" (Z).

$$
\mu_{\text {Alto }}(R P N)=\left\{\begin{array}{c}
0 ; \quad \mathrm{Z} \leq 625 \\
1-\frac{750-Z}{750-625} \quad 625<\mathrm{Z} \leq 750 \\
1-\frac{Z-750}{875-750 ;} \quad 750<\mathrm{Z}<875 \\
0 ; \quad 875 \leq \mathrm{Z}
\end{array}\right.
$$


Equation (12). RPN Fuzzy Set “Very High" (Z).

$$
\mu_{\text {Very High }}(N P R)=\left\{\begin{array}{c}
0 ; \quad \mathrm{Z} \leq 750 \\
1-\frac{875-Z}{875-750} ; \quad 750<\mathrm{Z} \leq 875 \\
1-\frac{\mathrm{Z}-875}{1000-875} ; \quad 875<\mathrm{Z}<1000 \\
0 ; \quad 1000 \leq \mathrm{Z}
\end{array}\right.
$$

The inference rules used for this Mamdani type model were considered according to the number of input variables and their sets, all possible combinations that represent the scenarios that can be presented given the conditions that are established were considered; as a result, 125 inference rules were formulated, the outputs were defined by specialists, to assign in each case the corresponding categorical rating of the RPN. These rules were introduced into the MATLAB model, as shown in the following figure (Figure 6).

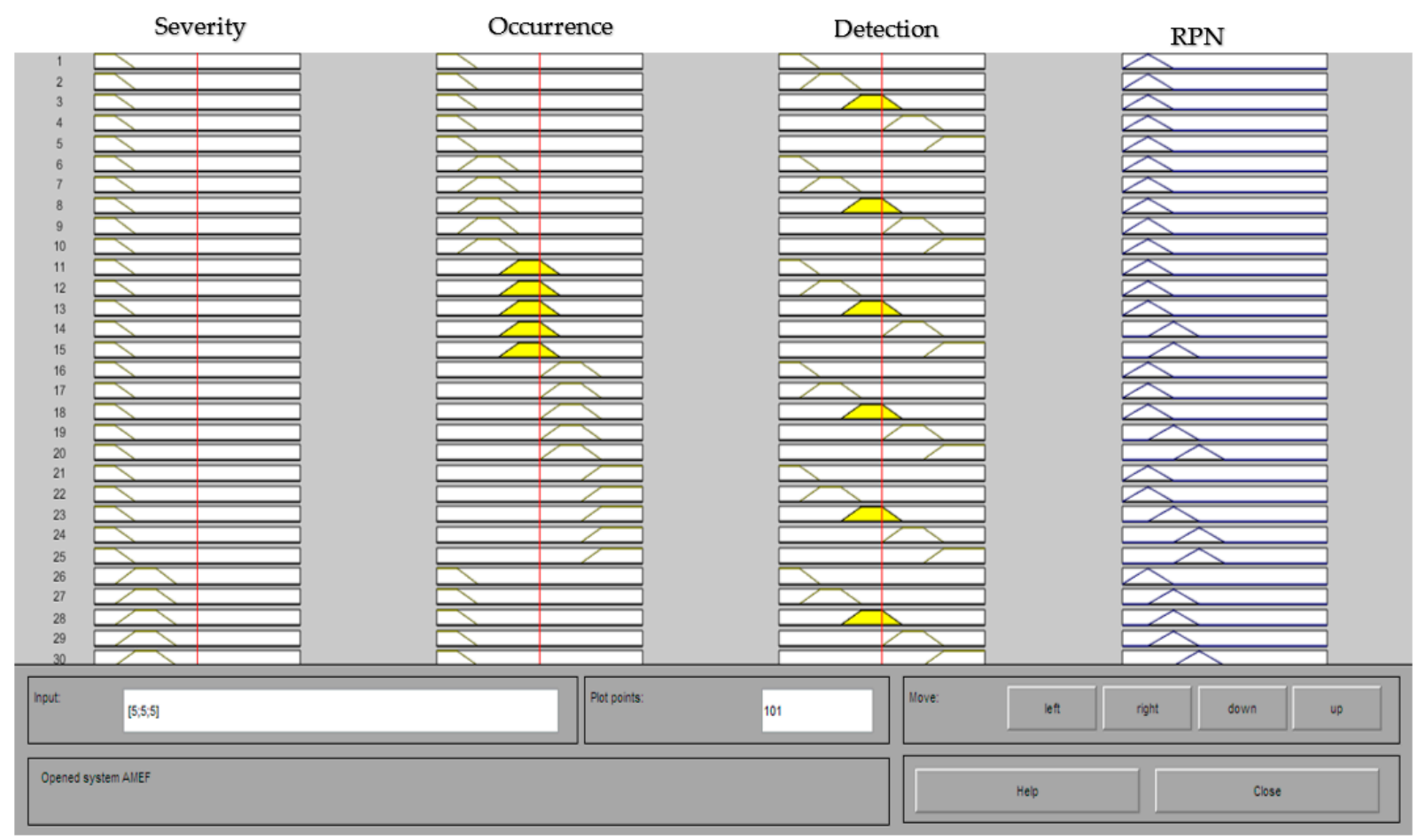

Figure 6. Mamdani Type Fuzzy Logic Model Inference Rules for Evaluating the Quantifying Prototype Source: Retrieved from MATLAB R2018b, Rule Viewer window screenshot, self-made content.

\subsection{Defuzzification Process}

The values that correspond to the sets of the RPN output variable are obtained numerically, according to the case of the rule activated in the Mamdani model when evaluating the different failure modes of the FMEA. The potential failure modes that were identified in the prototype were 30. Each failure mode was assessed using the defuzzification method above, and the values obtained from RPN are as shown below (Table 8). 
Table 8. Defuzzification of the RPN variable from the Mamdani model was applied to the quantifying prototype.

\begin{tabular}{cc}
\hline Failure Mode & RPN Fuzzy Model \\
\hline 1 & 625 \\
2 & 250 \\
3 & 625 \\
4 & 625 \\
5 & 375 \\
6 & 500 \\
7 & 500 \\
8 & 375 \\
9 & 375 \\
10 & 250 \\
11 & 125 \\
12 & 375 \\
13 & 125 \\
14 & 625 \\
15 & 125 \\
16 & 375 \\
17 & 375 \\
18 & 125 \\
19 & 750 \\
20 & 500 \\
21 & 125 \\
22 & 500 \\
23 & 125 \\
24 & 125 \\
25 & 500 \\
26 & 375 \\
27 & 375 \\
28 & 250 \\
29 & 125 \\
30 & 250 \\
\hline &
\end{tabular}

As shown in the table above, the RPN values obtained from the Mamdani model are repeated between some failure modes. This is because the values provided by the "Center of Gravity" defuzzification method have not been manipulated, but left by default in the Mamdani model, and in this way only one rule is activated per failure mode as the case may be, and although the sets that make up the rules are several of these coincide since in the output variable you only have seven sets, but if instead of leaving the default values that allow only one rule to be activated when the input sets are provided and the input values of each variable will be manipulated, more rules could be activated at the same time so that the value in the output may be different from the seven that are repeated. This would occur when the provided values enter the regions of intersection between sets, and what this causes is that other rules are activated and the result is different depending on these rules and the method of defuzzification used.

For this case, the default values have been left since the evaluation was intended to be carried out around using the linguistic terms of input so that only the necessary rule will be activated.

\subsection{Response Surfaces}

In this type of application, the use of the response surfaces that result from the Mamdani model of MATLAB are not a direct resource to obtain the type of result that is sought, which is to obtain the level of risk in a particular way in the sets of the output variable. However, these surfaces allow us to visualize and understand the logic that exists in the graphical representation of the RPN. That means the risk assessment is possible once the fuzzy rules have been established as a precedent in the inference base of the system. 
Therefore, a detailed analysis of the surfaces is not necessary in this model as in other application cases.

\section{Discussion}

With the defuzzification method "Center of Gravity", it was possible to obtain the RPN results for each mode of failure of the FMEA, as shown in the following figure (Figure 7). The numbering of the "failure modes" corresponds to that presented in the format of Table 7.

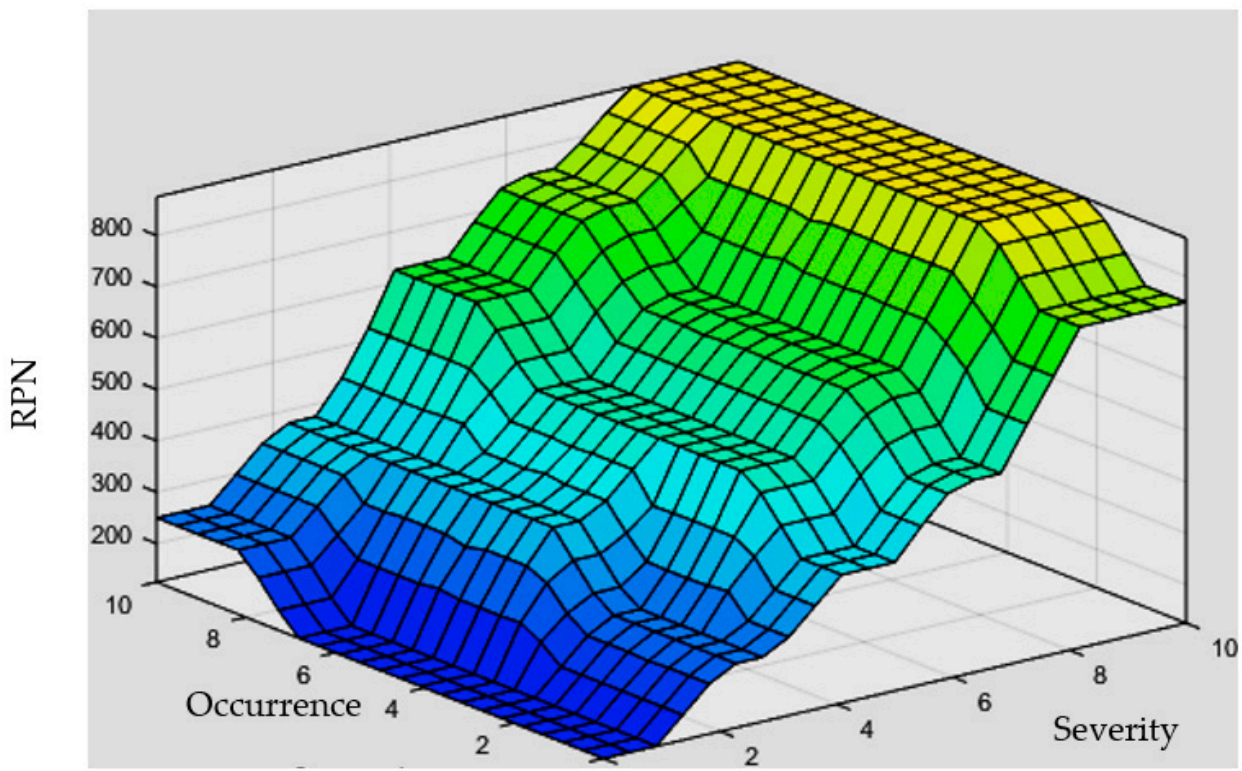

Figure 7. Response Surface Occurrence vs. Severity of the Risk Assessment Model to Failure Source: MATLAB R2018b software capture, self-developed content.

The response surfaces generated from the model are shown in Figures 8 and 9. In them, you can see how the level of risk increases or decreases depending on the input criteria Severity, Occurrence, and Detection, when these tend to take a certain value on the lower axes of the three-dimensional plane.

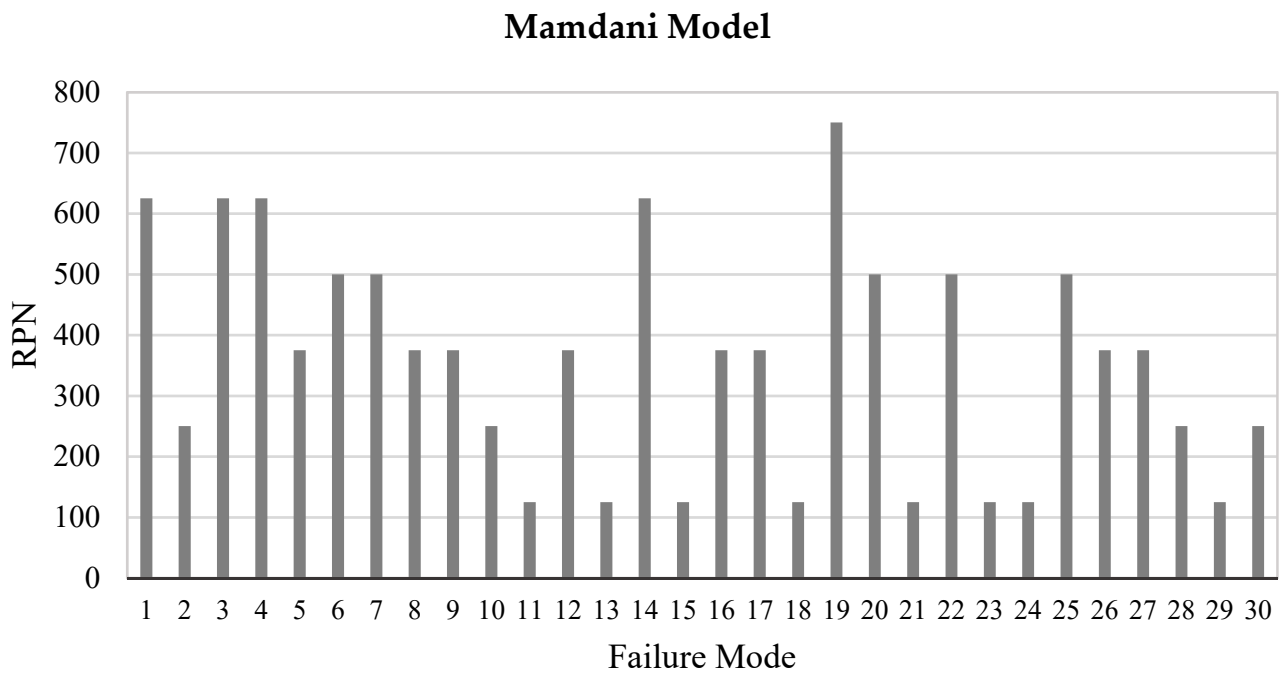

Figure 8. Representation of the Risk Priority Number by the Fuzzy Logic model. 


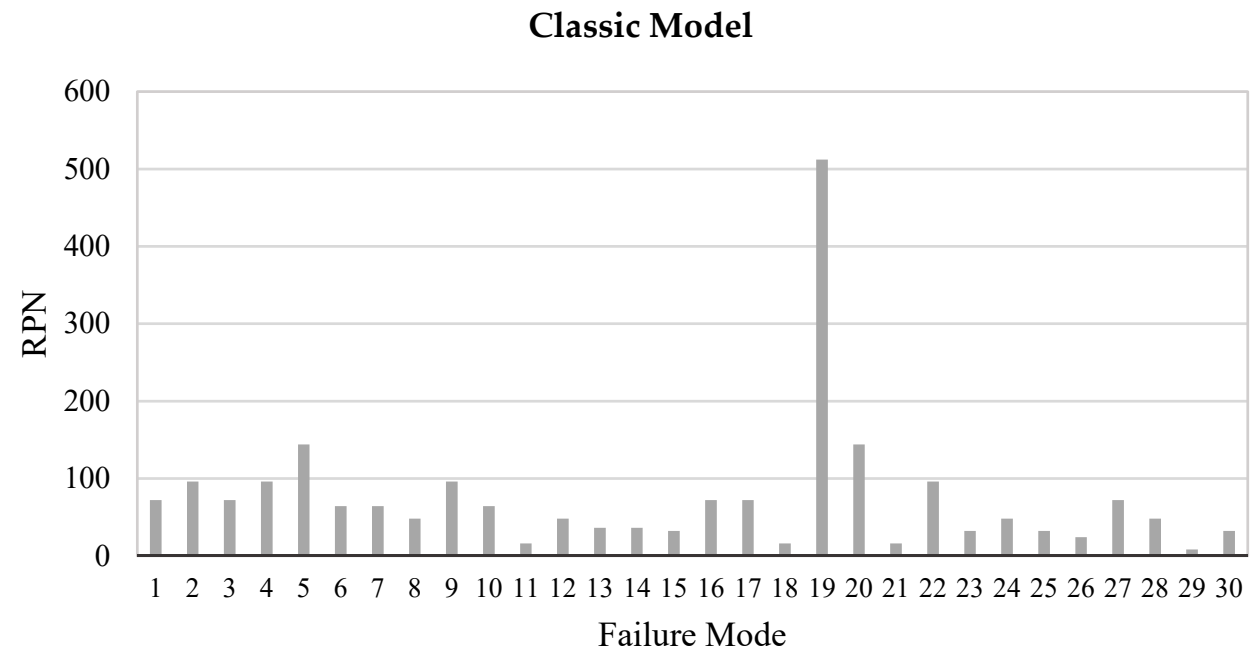

Figure 9. Representation of the Risk Priority Number by the classic model.

The results obtained from the methods used (classic FMEA and Fuzzy FMEA) to evaluate the RPN show asymmetric graphs. In the classical method, the values are mostly lower compared to the results of the Mamdani model; this is due to the description of the criteria with which it is evaluated.

There are two main reasons why the results vary significantly. The evaluation criteria in the Fuzzy Logic model for the FMEA have been appropriate to the context of the problem so that both linguistic and numerical values have a very different meaning in the evaluation.

In the classical method, the criteria used do not fit or comprehensively represent the context of what is being evaluated; obtaining the RPN is given through the multiplication of the evaluation criteria (Severity $x$ Occurrence $x$ Detection) in this method, not always the failures with greater severity are the priority.

It sometimes happens that failures with less severity but with higher value of occurrence or detection when multiplied, give a higher RPN value and take higher priority; that is, the priority depends in the first instance on the highest RPN value based on the evaluation parameters, without considering their relevance and only when the values are repeated, then the individual criteria assessment is deemed to be determined according to their significance which should go first.

Severity is addressed first because it relates to the effects of failures; Detection is used over the Occurrence because it depends on the client, which is more important than just failure frequencies (Stamatis, 2003); however, due to this classic method of obtaining, priority is given to failures with a higher number of RPN than to those with greater Severity.

The method used in the Mamdani model to obtain the RPN is inference through rules, and these are established according to the knowledge and reasoning of specialists about the level or intensity of the evaluation criteria; in this method, the highest RPN is assigned based on the relevance suggested in the literature of the evaluation criteria, in the order: Severity, Detection, and Occurrence, therefore the values obtained from the Mamdani model are considered with greater validity, and because the description of each criterion has been appropriate to the specific situation of the problem, therefore the results are more representative than in a conventional way.

The relevant fundamentals of the classic FMEA are described and later the use of fuzzy set theory is proposed as an alternative to reduce the uncertainty that can be generated by the NPR calculated with the traditional method, hence the disparity of data mentioned is made between Figures 8 and 9. The review shows the context in which the technique may be more appropriate and highlights the potential usefulness of fuzzy set theory to address uncertainty specifically in this case study, in software engineering, security and reliability.

There are methodologies applied to security and reliability engineering, which include fuzzy FMEA [1]. When prototypes are developed, it is not always possible to obtain 
reliable data; this is because they are recently created and, in most cases, due to the lack of availability of primary observations and the scarcity of data on the failure of their components. It is also difficult to establish risk parameters. To handle such situations, fuzzy set theory is an alternative for the evaluation of security and reliability under conditions of uncertainty, such as what is presented in this work.

\section{Conclusions}

The description of recommended actions for this case was established for failure modes whose RPN values were equivalent to those of the fuzzy "Significant" set, whose value was equal to or greater than 250. The FMEA methodology aims at continuous improvement, so it is necessary to carry it out periodically to identify failures and establish actions, in this case being a prototype, and it is essential to develop improvement actions for most failures to ensure operation, so it was determined to establish as a reference a low RPN for the context of the problem, to address most of the prototype's shortcomings and then re-evaluate the results.

It can be seen that in the classical method, the values are mostly lower compared to the results of the Mamdani model; this is due to the description of the criteria with which it is evaluated, and it can be said that there are two main reasons why the results vary significantly. One is that the evaluation criteria in the Fuzzy Logic model have been appropriate to the context of the problem so that both linguistic and numerical values have a very different meaning in the evaluation, while in the classical method the criteria used do not fit or represent in their entirety the context of what is evaluated.

The implementation of the Fuzzy FMEA allowed us to collect, order, and evaluate the information of the prototype concerning the operational failures of the different components; it can be said that the design of the studied quantifier is better in some important characteristics compared to other prototypes designed for the same purpose, however; the operating uncertainty conditions to which the quantifier is subjected affect the precision. Specifically, they are the characteristics related to the configuration or arrangement of the sensors to the tube of the animal that needs to be modified so that the sensors are no longer affected since, by their design and location, they suffer rubbing with solid surfaces that damage them. In general terms, these are the aspects that need to be improved to achieve greater accuracy.

Author Contributions: L.C.-R.: conceptualization, writing—original draft preparation, methodology and research; A.A.A.-L.: software and research; C.E.M.-O.: formal analysis and investigation; J.S.-E.: writing—original draft preparation; A.B.-M.: review and editing; M.L.M.-H.: supervision and project administration. All authors have read and agreed to the published version of the manuscript.

Funding: This research received no external funding

Institutional Review Board Statement: Not applicable

Informed Consent Statement: Not applicable

Acknowledgments: To TECNM/ Instituto Tecnológico Superior de Tantoyuca, Francisco Osorio, and Michelle Castillo for the support.

Conflicts of Interest: The authors declare no conflict of interest.

\section{References}

1. Kabir, S.; Papadopoulos, Y. A Review of Applications of Fuzzy Sets to Safety and Reliability Engineering. Int. J. Approx. Reason. 2018, 100, 29-55. [CrossRef]

2. Chanamool, N.; Naenna, T. Fuzzy FMEA Application to Improve Decision-Making Process in an Emergency Department. Appl. Soft Comput. 2016, 43, 441-453. [CrossRef]

3. Batbayar, K.; Takacs, M.; Kozlovszky, M. Medical Device Software Risk Assessment Using FMEA and Fuzzy Linguistic Approach: Case Study; Institute of Electrical and Electronics Engineers (IEEE): Piscataway, NJ, USA, 2016; pp. 197-202. [CrossRef]

4. Li, Z.; Chen, L. A Novel Evidential FMEA Method by Integrating Fuzzy Belief Structure and Grey Relational Projection Method. Eng. Appl. Artif. Intell. 2019, 77, 136-147. [CrossRef] 
5. Yazdi, M.; Daneshvar, S.; Setareh, H. An Extension to Fuzzy Developed Failure Mode and Effects Analysis (FDFMEA) Application for Aircraft Landing System. Saf. Sci. 2017, 98, 113-123. [CrossRef]

6. Zhou, Y.; Xia, J.; Zhong, Y.; Pang, J. An Improved FMEA Method Based on the Linguistic Weighted Geometric Operator and Fuzzy Priority. Qual. Eng. 2016, 28, 491-498. [CrossRef]

7. Grossi, G.; Goglio, P.; Vitali, A.; Williams, A. Livestock and Climate Change: Impact of Livestock on Climate and Mitigation Strategies. Anim. Front. 2019, 9, 69-76. [CrossRef] [PubMed]

8. Silva-Martínez, K.L.; Cruz-Rivero, L.; Arrieta-González, A.; Purroy-Vasquez, R. Non-Invasive Measurer for Methane and Carbone Dioxide Emissions in Bovine Cattle through TRIZ. Agron. Res. 2020, 18, 1018-1026. [CrossRef]

9. Cruz-Rivero, L.; Mateo-Diaz, N.F.; Purroy-Vasquez, R.; Angeles-Herrera, D.; Osorio-Cruz, F. Statistical Analysis for a NonInvasive Methane Gas and Carbon Dioxide Measurer for Ruminants. In Proceedings of the 2020 IEEE International Conference on Engineering Veracruz (ICEV), Boca del Rio, Mexico, 26-29 October 2020; Institute of Electrical and Electronics Engineers (IEEE): Piscataway, NJ, USA, 2020; pp. 1-7. [CrossRef]

10. Stamatis, D. Failure Mode and Effect Analysis: FMEA from Theory to Execution; American Society for Quality: Milwaukee, WI, USA, 2003

11. Jin, C.; Ran, Y.; Zhang, G. Interval-Valued Q-Rung Orthopair Fuzzy FMEA Application to Improve Risk Evaluation Process of Tool Changing Manipulator. Appl. Soft Comput. 2021, 104, 107192. [CrossRef]

12. Boral, S.; Howard, I.; Chaturvedi, S.K.; McKee, K.; Naikan, V. An Integrated Approach for Fuzzy Failure Modes and Effects Analysis Using Fuzzy AHP and Fuzzy MAIRCA. Eng. Fail. Anal. 2020, 108, 104195. [CrossRef]

13. Yeganeh, A.; Heravi, M.Y.; Razavian, S.B.; Behzadian, K.; Shariatmadar, H. Applying a New Systematic Fuzzy FMEA Technique for Risk Management in Light Steel Frame Systems. J. Asian Arch. Build. Eng. 2021, 20, 1-22. [CrossRef]

14. Ribas, J.R.; Severo, J.C.R.; Guimarães, L.F.; Perpetuo, K.P.C. A Fuzzy FMEA Assessment of Hydroelectric Earth Dam Failure Modes: A Case Study in Central Brazil. Energy Rep. 2021, 7, 4412-4424. [CrossRef]

15. Mamdani, E.H. Application of Fuzzy Logic to Approximate Reasoning Using Linguistic Synthesis. IEEE Trans. Comput. 1977, C-26, 1182-1191. [CrossRef]

16. Castillo, O.; Aguilar, L.T. Fuzzy Control Synthesis for Systems with Discontinuous Friction. In Type-2 Fuzzy Logic in Control of Nonsmooth Systems: Studies in Fuzziness and Soft Computing; Springer Science and Business Media: Cham, Switzerland, 2018; Volume 373, pp. 73-83. [CrossRef] 